\title{
Two Element Planar Dipole Array Antenna for Wireless LAN
}

\author{
Mitsuo Taguchi ${ }^{(1)}$, Daisuke Iwanaka ${ }^{(2)}$, Tetsuya Yamashita ${ }^{(3)}$ \\ (1), (3) Dept. of Electrical \& Electronic Eng., Nagasaki University \\ ${ }^{(2)}$ Graduate School of Science and Technology, Nagasaki University \\ 1-14 Bunkyo-machi, Nagasaki-shi, 852-8521, Japan \\ E-mail: ${ }^{(1)}$ mtaguchi@nagasaki-u.ac.jp, ${ }^{(2)}$ d707136e@cc.nagasaki-u.ac.jp, \\ (3)s604069c@cc.nagasaki-u.ac.jp
}

\section{Introduction}

Recently, the demand for Broadband Internet Connection has been expanded. However, a lot of digital divide areas still exist. In these areas, the introduction of optical fiber and public wireless LAN is difficult in terms of profitability. As the countermeasure to these digital divide, the introduction of "Wireless LAN Mesh Networks" is under consideration in Japan in order to construct a wide wireless LAN at low cost [1]. For this purpose, the antenna of a high directivity is necessary.

As the directional antenna composed of wire elements, the Yagi-Uda antenna and the Electronically Steerable Passive Radiator (ESPAR) antenna are well known [2], [3]. These antennas consist of single driven element and some parasitic elements. These antennas are spatially phase controlled antennas. Authors have proposed the two element array dipole antenna with $90^{\circ}$ phase difference feed through a $90^{\circ}$ hybrid phase shifter for the directional antenna [4]. The front-to-back ratio of $15.3 \mathrm{~dB}$ is obtained in the reference [4].

In this paper, two element planar dipole array fed by the parallel line without using a hybrid phase shifter is proposed for the $2.4 \mathrm{GHz}$ band wireless LAN. This antenna is numerically and experimentally analyzed. In the numerical analysis, the electromagnetic simulator "WIPL-D" based on the method of moment is used $[5]$.

\section{Structure of the antenna and analytical conditions}

Figure 1 shows the structure of the proposed antenna. Two dipole elements are fed by the parallel line printed on both sides of the dielectric layer. The width of parallel line is $\mathrm{W}_{\mathrm{p}}$, and those of the elements $\# 1$ and $\# 2$ are $\mathrm{W}_{1}$ and $\mathrm{W}_{2}$, respectively. The length between the feed point and the element \#1 is D. The distance between the element $\# 1$ and the element $\# 2$ is $D_{12}$. The lengths of element $\# 1$ and $\# 2$ are $L_{1}$ and $L_{2}$, respectively. The thickness of the dielectric layer $T_{1}$ is $0.8 \mathrm{~mm}$ and thickness of conductor $\mathrm{T}_{2}$ is $0.018 \mathrm{~mm}$. The relative permittivity and the loss tangent of dielectric material are 2.15 and 0.001 , respectively. The calculation frequencies are from $2.3 \mathrm{GHz}$ to $2.6 \mathrm{GHz}$. 


\section{Numerical and experimental results}

Figure 2 shows the current distribution at the frequency $2.4 \mathrm{GHz}$. Although the distance between two elements $D_{12}$ is 0.112 wavelength, the phase difference of currents on two elements is 161 degrees. In this case, the directivity is $6.73 \mathrm{dBi}$.

Figure 3 shows the directivity and the front-to-back (FB) ratio as a function of distance between two elements $\mathrm{D}_{12}$ at $2.4 \mathrm{GHz}$. Figure 4 shows the directivity and the FB ratio as a function of length of element $\# 1 \mathrm{~L}_{1}$ at $2.4 \mathrm{GHz}$.

The structure of antenna is adjusted to obtain the good return loss and the directivity. Figure 5 shows the calculated and measured return loss characteristics of the optimized model. The difference between the calculated and measured resonance frequencies is $44 \mathrm{MHz}$ (relative error of $1.8 \%$ at $2.45 \mathrm{GHz}$ ).

Figure 6 shows the calculated electric field radiation patterns of this antenna at 2.4, 2.45 and $2.5 \mathrm{GHz}$. The calculated directivities are $6.80 \mathrm{dBi}, 6.90 \mathrm{dBi}$ and $6.69 \mathrm{dBi}$ are obtained at $2.4 \mathrm{GHz}, 2.45 \mathrm{GHz}$ and $2.5 \mathrm{GHz}$, respectively.

\section{Conclusion}

In this paper, two element planar dipole array antenna fed by the parallel line has been proposed for $2.4 \mathrm{GHz}$ band wireless LAN mesh network. In the numerical analysis, the electromagnetic simulator "WIPL-D" based on the method of moment is used. This antenna is numerically and experimentally analyzed. The current distributions of antenna elements are controlled by adjusting the lengths of dipole elements and the distance between them. The directivity of more than $6.69 \mathrm{dBi}$ has been obtained from $2.4 \mathrm{GHz}$ to $2.5 \mathrm{GHz}$.

In the next step, the proposed antenna will be located radially with respect to the feed point.



(a) Top view



(b) Only conductor

Figure 1 Structure of antenna 


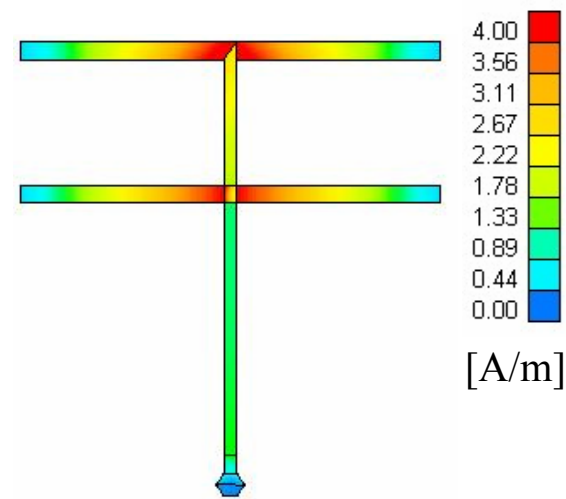

(a) Amplitude



Figure 2 Current distribution at $2.4 \mathrm{GHz}$

$\mathrm{W}_{\mathrm{p}}=1.5 \mathrm{~mm}, \mathrm{~W}_{1}=2.0 \mathrm{~mm}, \mathrm{~W}_{2}=2.0 \mathrm{~mm}, \mathrm{D}=30 \mathrm{~mm}, \mathrm{D}_{12}=14 \mathrm{~mm}, \mathrm{~L}_{1}=22.5 \mathrm{~mm}$, $\mathrm{L}_{2}=22.5 \mathrm{~mm}$

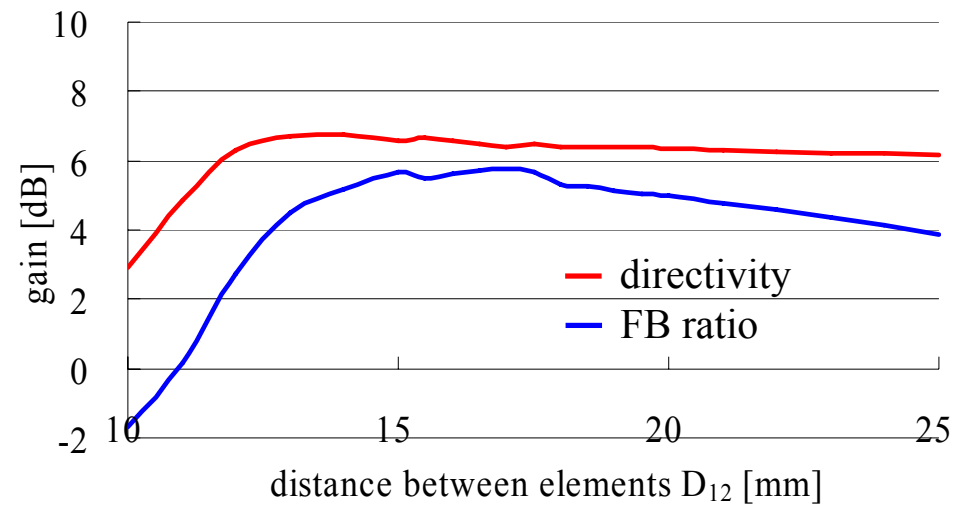

Figure 3 Directivity and FB ratio vs. distance between elements $\mathrm{D}_{12}$ at $2.4 \mathrm{GHz}$ $\mathrm{W}_{\mathrm{p}}=1.5 \mathrm{~mm}, \mathrm{~W}_{1}=2.0 \mathrm{~mm}, \mathrm{~W}_{2}=2.0 \mathrm{~mm}, \mathrm{D}=30 \mathrm{~mm}, \mathrm{~L}_{1}=22.5 \mathrm{~mm}, \mathrm{~L}_{2}=22.5 \mathrm{~mm}$



Figure 4 Directivity and FB ratio vs. length of element $\# 1 \mathrm{~L}_{1}$ at $2.4 \mathrm{GHz}$ $\mathrm{W}_{\mathrm{p}}=1.5 \mathrm{~mm}, \mathrm{~W}_{1}=2.0 \mathrm{~mm}, \mathrm{~W}_{2}=2.0 \mathrm{~mm}, \mathrm{D}=30 \mathrm{~mm}, \mathrm{D}_{12}=17 \mathrm{~mm}, \mathrm{~L}_{2}=22.5 \mathrm{~mm}$ 


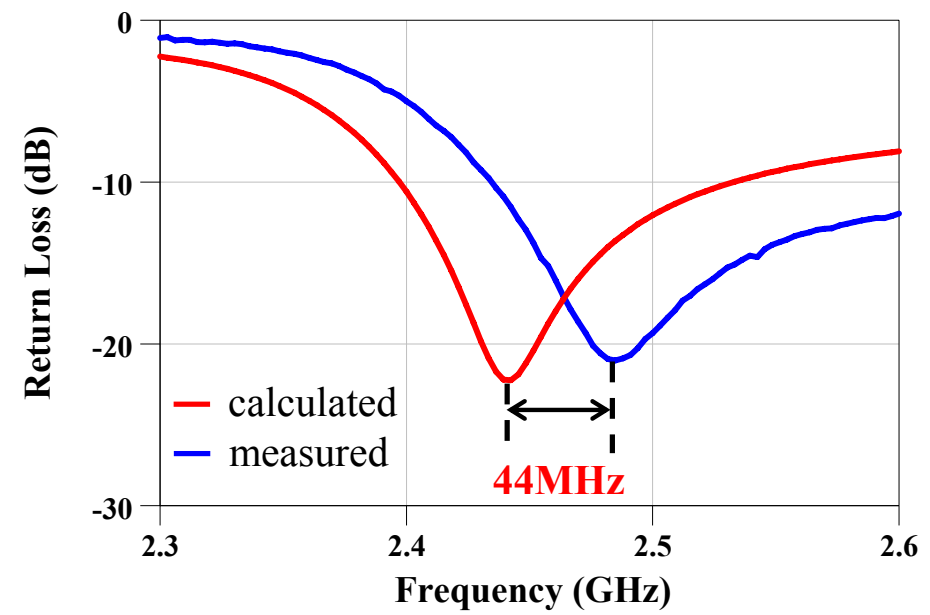

Figure 5 Return loss characteristics of the optimized model $\mathrm{W}_{\mathrm{p}}=2.0 \mathrm{~mm}, \mathrm{~W}_{1}=2.8 \mathrm{~mm}, \mathrm{~W}_{2}=1.9 \mathrm{~mm}, \mathrm{D}=40 \mathrm{~mm}, \mathrm{D}_{12}=15.8 \mathrm{~mm}$, $\mathrm{L}_{1}=23 \mathrm{~mm}, \mathrm{~L}_{2}=19.2 \mathrm{~mm}$

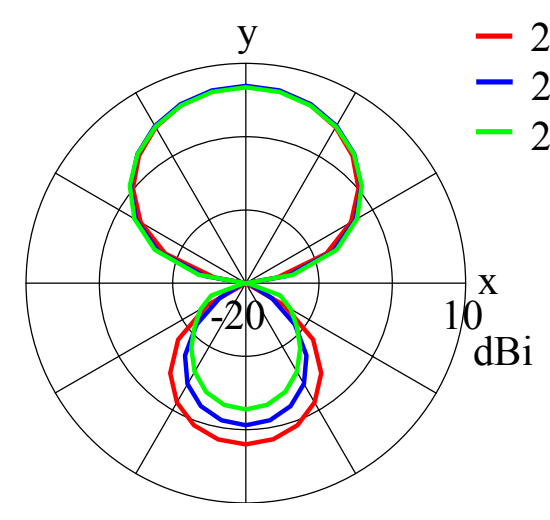

(a) xy plane

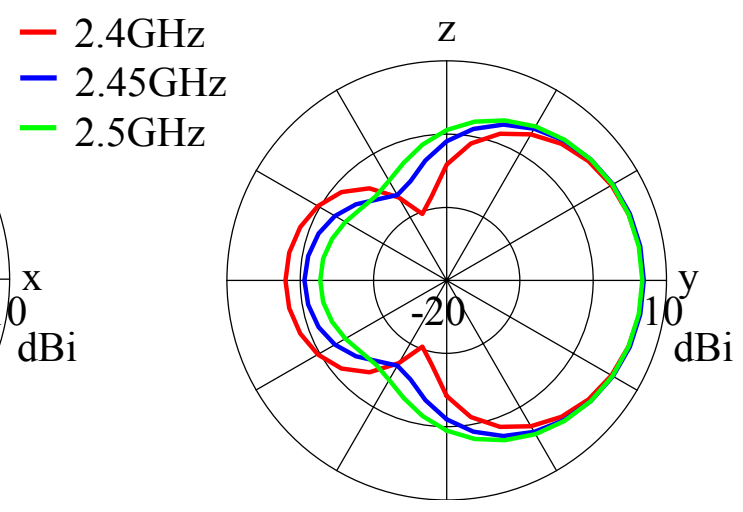

(b) yz plane

Figure 6 Electric field radiation pattern of the optimized model $\mathrm{W}_{\mathrm{p}}=2.0 \mathrm{~mm}, \mathrm{~W}_{1}=2.8 \mathrm{~mm}, \mathrm{~W}_{2}=1.9 \mathrm{~mm}, \mathrm{D}=40 \mathrm{~mm}, \mathrm{D}_{12}=15.8 \mathrm{~mm}$, $\mathrm{L}_{1}=23 \mathrm{~mm}, \mathrm{~L}_{2}=19.2 \mathrm{~mm}$

\section{References}

[1] M. Taguchi, T. Yamashita, D. Iwanaka, "Study on antenna of 6 dipole elements for wireless LAN" ITE Technical Report, pp. 13-16, Jan. 2008 (in Japanese).

[2] H. Yagi, "Beam transmission of ultra-short waves," Proc. IRE, vol. 16, p. 715, 1928.

[3] T. Ohira and K. Gyoda, "Electronically steerable passive array radiator antennas for low-cost analog adaptive beam-forming," Proc. IEEE Int. Conf. on Phased Array Systems and Technology, pp. 101-104, May 2000.

[4] M. Taguchi, K. Era, K. Tanaka, "Two element phased array dipole antenna," ACES Journal, vol. 22, no. 1, pp. 112-116, March 2007.

[5] "WIPL-D Pro v6.4 3D Electromagnetic Solver Professional Edition User's Manual” WIPL-D Ltd., 2007 